\title{
Effect of Drug Sample Removal on Pre- scribing in a Family Practice Clinic
}

\author{
Daniel M. Hartung, PharmD, MPH \\ David Evans, $M D^{2}$ \\ Dean G. Haxby, PharmD ${ }^{1}$ \\ Dale F. Kraemer, $P b D^{1}$ \\ Gabriel Andeen ${ }^{3}$ \\ Lyle J. Fagnan, $M D^{3}$ \\ ${ }^{1}$ Department of Pharmacy Practice, Oregon \\ State University College of Pharmacy, Port- \\ land, Oregon \\ ${ }^{2}$ Madras Medical Group, Madras, Oregon \\ ${ }^{3}$ Oregon Rural Practice-based Research \\ Network; Department of Family Practice, \\ School of Medicine, Oregon Health \& Sci- \\ ence University, Portland, Oregon
}

Conflicts of interest: none reported

\section{CORRESPONDING AUTHOR}

Daniel M. Hartung, PharmD, MPH

3303 SW Bond Ave; $\mathrm{CH} 12 \mathrm{C}$

Portland, OR 97239

hartungd@ohsu.edu

\begin{abstract}
PURPOSE Little is known about the impact of recent restrictions on pharmaceutical industry detailing and sampling on prescribing behavior, particularly within smaller, independent practices. The objective of this study was to evaluate the effect of a policy prohibiting prescription drug samples and pharmaceutical industry interaction on prescribing patterns in a rural family practice clinic in central Oregon.
\end{abstract}

METHODS Segmented linear regression models were used to evaluate trends in prescribing using locally obtained pharmacy claims. Oregon Medicaid pharmacy claims were used to control for secular prescribing changes. Total and class-specific monthly trends in branded, promoted, and average prescription drug costs were analyzed 18 months before and after policy implementation.

RESULTS Aggregate trends of brand name drug use did not change significantly after policy implementation. In aggregate, use of promoted agents decreased by $1.43 \%$ while nonpromoted branded agents increased by $3.04 \%$. Branded drugs prescribed for respiratory disease declined significantly by $11.34 \%$ compared with a control group of prescribers. Relative to the control group, prescriptions of promoted cholesterol-lowering drugs and antidepressants were reduced by approximately $9.98 \%$ and $11.34 \%$, respectively. The trend in average cost per prescription for lipid-lowering drugs was significantly reduced by $\$ 0.70$ per prescription per month. Overall, average prescription drug costs increased by $\$ 5.18$ immediately after policy implementation.

CONCLUSIONS Restriction of pharmaceutical industry representatives and samples from a rural family practice clinic produced modest reductions in branded drug use that varied by class. Although aggregate average costs increased, prescriptions for branded and promoted lipid-lowering agents and antidepressants were reduced.

Ann Fam Med 2010;8:402-409. doi:10.1370/afm.1135.

\section{INTRODUCTION}

T 2003 the pharmaceutical industry spent $\$ 25.3$ billion on drug promotional activities, including approximately $\$ 16$ billion on free samples and $\$ 7.3$ billion on direct detailing to doctors. ${ }^{1,2}$ Studies have shown that $80 \%$ to $95 \%$ of physicians meet regularly with sales representatives. Family physicians who met with industry representatives an average of 16 times a month were more likely to interact with industry than clinicians from other specialties. A large literature supports the notion that industry detailing and drug samples have a strong impact on prescribing behavior, leading to irrational prescribing patterns, increased branded mediation use, and the use of non-first-line agents. ${ }^{3-9}$

The impact of marketing practices and potential financial conflict of interest between physicians and industry have raised concern among the public and academic institutions about the ethics of pharmaceutical industry marketing and detailing. ${ }^{10-17}$ Such concern has lead many academic institutions to develop clear policies defining and limiting interac- 
tion of industry representatives with clinical faculty, house staff, and medical students. ${ }^{18}$ Little evidence exists, however, concerning the development of individual clinic policies regarding access of pharmaceutical representatives, the use of drug samples, and how such policies might affect prescribing practices of physicians.

In January of 2006, the Madras Medical Group (MMG), a small private practice clinic in central Oregon, discontinued seeing pharmaceutical representatives and stopped accepting and distributing drug samples. Located in a rural area with few pharmacies and limited managed-care penetration, the $\mathrm{MMG}$ experience represents a unique opportunity to study the impact of how a locally developed clinic policy restricting access of pharmaceutical representatives and samples can affect clinic prescribing patterns. The objective of this project was to evaluate changes in prescribing patterns after the introduction of the MMG sampling policy.

\section{METHODS}

Madras is a rural town of about 6,000 residents situated in central Oregon. The MMG, which employs 5 physicians and 1 physician assistant, is the primary ambulatory medical clinic in Madras. Approximately $30 \%$ of the clinic panel has health insurance coverage through Medicare, 30\% through private insurance, and $25 \%$ through Medicaid; $15 \%$ are self-paying.

There are 3 pharmacies in Madras; however, most patients served at MMG are known to fill prescriptions at the town's independent pharmacy (Thrifty Hometown Drug). Unidentified pharmacy claims, between April 1, 2004, to September 31, 2007, from prescribers practicing at $\mathrm{MMG}$, were obtained from Thrifty Hometown Drug pharmacy. Trends in brand name prescribing, promoted drug prescribing, and drug costs were analyzed using an observational segmented linear regression approach that compared utilization trends at MMG before and after implementation of the drug sampling policy. ${ }^{19}$ Utilization trends within MMG were then compared with control trends obtained from the Oregon Medicaid program. The Medicaid control group was further restricted to family practice prescribers in Jackson County, Oregon, a region geographically removed from the study area. In January 2006 the Medicare Part D program was implemented, and all Medicaid/Medicare dual-eligible patients were transitioned from Medicaid to Medicare for most of their pharmacy benefits. To minimize the impact of abrupt censoring of dual-eligible pharmacy claims after January 2006, these patients were excluded from the control group.
Three outcome variables were developed for the analysis: percentage of branded drug use, percentage of promoted drug use, and average prescription costs. We identified promoted drugs by selecting agents known to be sampled at MMG before the policy or heavily promoted at the time. All investigators reached consensus on the list of promoted drugs, which can be found in the Supplemental Appendix 1, available online at http://annfammed.org/cgi/ content/full/8/5/402/DC1. We assessed changes in prescription drug costs in aggregate, as well as within therapeutic classes, and converted drug costs from the Madras pharmacy to a standardized Medicaid reimbursement rate to adjust for the variety of payers in the MMG group. The distribution of aggregated cost data by group in total and by drug class did not exhibit large departures from normality and therefore were not transformed.

In addition to the aggregated analyses, we explored trends within 4 specific drug classes: antidepressants, antihypertensives, lipid-lowering drugs, and allergy and respiratory drugs (respiratory drugs). A list of drugs included in each of these categories can be found in Supplemental Appendix 2, available at http:// annfammed.org/cgi/content/full/8/5/402/DC1. Short-acting $\beta_{2}$-adrenergic agonists were excluded from the respiratory drug category because concurrent changes occurring with inhaler reformulation introduced volatility into the trends within this class.

Monthly aggregated and drug-class-specific trends from April 1, 2004, to September 31, 2007 (21 months before policy implementation, 21 months after policy implementation), were used as dependent variables in 3 sets of segmented linear regression models to assess changes in prescribing temporally related to the MMG's policy changes. Monthly utilization 3 months before and after policy implementation (October 2005 through March 2006) were excluded to accommodate a gradual transition period (18 months before and after).

Ordinary least squares regression requires that several assumptions, such as independence of observations, be met to generate unbiased estimates. Because adjacent time series data are not independent (ie, an observation in 1 month is associated with the observation in the previous month), specialized techniques are required to accommodate this violation (first-degree autocorrelation of errors). We used the autoregressive corrective procedure (PROC AUTOREG in SAS, version 9, SAS Institute, Cary, North Carolina) to correct for first-degree, serially correlated data and to evaluate the significance of immediate and trend changes after policy implementation. ${ }^{19}$

Because 6 months of data were excluded to accommodate a gradual implementation, immediate changes 
reflect significant increases or decreases occurring from month 18 (September 2005) to month 25 (April 2006). Models were fit for brand name prescribing, promoted drug prescribing, and average drug cost per prescription in aggregate and for the 4 therapeutic classes.

For all models, $\beta$ coefficients from regression models are expressed in 2 ways. First, trends in utilization, that is, the slope in utilization over time, is expressed as the trend before policy implementation, or pre trend $(\beta 1)$, and the change in this trend after policy implementation, or trend change $(\beta 3)$. Second, the level change $(\beta 2)$ describes immediate changes in the modeled utilization after the policy implementation and is expressed as an absolute increase or decrease of the model outcome variable (eg, percentage dispensed brand). Finally, a bivariate interaction term was added to the model to investigate the difference in the prescribing pattern estimates between MMG prescriptions and the control prescribing sample.
This project was approved by the Oregon Health \& Science University Institutional Review Board. Data were manipulated using Microsoft Access and Excel. Statistical analyses were conducted using SAS version 9 for Windows.

\section{RESULTS}

During the study, 92,223 pharmacy claims were processed for the MMG and 178,028 were processed within the control series. Analysis of branded drug use trends are shown in Table 1. Aggregate levels of brand name drug use did not change significantly after the policy was implemented. The trend changes in prescribed branded antihypertensive and lipid-lowering drugs were significantly reduced after policy implementation; however, relative to the control group, these changes did not remain statistically significant. A significant reduction in the level change of branded

Table 1. Trends in Branded Drug Prescribing Before and After Policy Implementation at Madras Medical Group (MMG) Alone and Relative to Control

\begin{tabular}{|c|c|c|c|c|c|c|}
\hline \multirow[b]{2}{*}{ Prescribing } & \multicolumn{3}{|c|}{ MMG Trend } & \multicolumn{3}{|c|}{ MMG Relative to Control } \\
\hline & $\begin{array}{c}\text { Estimate } \\
\%\end{array}$ & $95 \% \mathrm{Cl}$ & $\begin{array}{c}P \\
\text { Value }\end{array}$ & $\begin{array}{c}\text { Estimate } \\
\%\end{array}$ & $95 \% \mathrm{Cl}$ & $\begin{array}{c}P \\
\text { Value }\end{array}$ \\
\hline \multicolumn{7}{|l|}{ Aggregate } \\
\hline Baseline level & 41.12 & 39.56 to 42.68 & $<.001$ & & & \\
\hline Pre trend & -0.34 & -0.48 to -0.19 & $<.001$ & -0.14 & -0.31 to 0.02 & .087 \\
\hline Level change $^{a}$ & 1.74 & -0.73 to 4.21 & .177 & 1.59 & -1.31 to 4.49 & .286 \\
\hline Post trend ${ }^{\mathrm{a}}$ & -0.38 & -0.73 to -0.03 & .688 & -0.20 & -0.59 to 0.20 & .676 \\
\hline \multicolumn{7}{|l|}{ Antidepressants } \\
\hline Baseline level & 45.24 & 41.10 to 49.38 & $<.001$ & & & \\
\hline Pre trend & -0.37 & -0.74 to 0.01 & .068 & -0.23 & -0.84 to 0.38 & .459 \\
\hline Level change ${ }^{a}$ & -1.44 & -8.26 to 5.38 & .683 & -7.79 & -18.16 to 2.58 & .146 \\
\hline Post trenda & -0.85 & -1.78 to 0.08 & .094 & 0.45 & -1.04 to 1.95 & .135 \\
\hline \multicolumn{7}{|l|}{ Antihypertensives } \\
\hline Baseline level & 30.77 & 29.09 to 32.45 & $<.001$ & & & \\
\hline Pre trend & 0.08 & -0.07 to 0.24 & .308 & 0.10 & -0.18 to 0.37 & .499 \\
\hline Level change ${ }^{\mathrm{a}}$ & 0.36 & -2.48 to 3.20 & .804 & -4.29 & -9.29 to 0.71 & .098 \\
\hline Post trenda & -0.54 & -0.92 to -0.16 & $<.001$ & 0.20 & -0.48 to 0.88 & .612 \\
\hline \multicolumn{7}{|c|}{ Lipid-lowering drugs } \\
\hline Baseline level & 75.64 & 70.64 to 80.64 & $<.001$ & & & \\
\hline Pre trend & -0.19 & -0.64 to 0.27 & .432 & -0.51 & -0.98 to -0.04 & .036 \\
\hline Level change ${ }^{\mathrm{a}}$ & 0.35 & -7.86 to 8.57 & .933 & -1.91 & -10.59 to 6.77 & .667 \\
\hline Post trenda & -1.36 & -2.48 to -0.24 & .002 & -1.03 & -2.17 to 0.10 & .132 \\
\hline \multicolumn{7}{|l|}{ Respiratory drugs } \\
\hline Baseline level & 85.45 & 80.67 to 90.23 & $<.001$ & & & \\
\hline Pre trend & -0.36 & -0.81 to 0.08 & .116 & -0.13 & -0.64 to 0.38 & .620 \\
\hline Level change ${ }^{a}$ & -11.93 & -20.08 to -3.78 & .007 & -11.34 & -20.75 to -1.93 & .021 \\
\hline Post trenda & 0.44 & -0.63 to 1.51 & .017 & 0.57 & -0.67 to 1.80 & .065 \\
\hline \multicolumn{7}{|c|}{ a Changes after policy implementation. } \\
\hline \multicolumn{7}{|c|}{$\begin{array}{l}\text { Note: Baseline level }=\text { prescribing rate at month } 1 \text { (April 2004); pre trend }=\text { monthly change in prescribing rate in period before policy implementation; level } \\
\text { change = change in prescribing rate immediately before policy implementation (September 2005) to immediately after policy implementation (April 2006); post } \\
\text { trend = monthly change in prescribing rate in period after policy implementation. MMG relative to control estimates are interpreted similarly, but adjusted for concur- } \\
\text { rent prescribing trends in the control group. }\end{array}$} \\
\hline
\end{tabular}




\begin{tabular}{|c|c|c|c|c|c|c|}
\hline \multirow[b]{2}{*}{ Prescribing } & \multicolumn{3}{|c|}{ MMG Trend } & \multicolumn{3}{|c|}{ MMG Relative to Control } \\
\hline & $\begin{array}{c}\text { Estimate } \\
\%\end{array}$ & $95 \% \mathrm{Cl}$ & $P$ Value & $\begin{array}{c}\text { Estimate } \\
\%\end{array}$ & $95 \% \mathrm{Cl}$ & $P$ Value \\
\hline \multicolumn{7}{|c|}{ Aggregate promoted } \\
\hline Baseline level & 10.00 & 9.46 to 10.54 & $<.001$ & & & \\
\hline Pre trend & 0.02 & -0.03 to 0.06 & .550 & -0.04 & -0.10 to 0.02 & .163 \\
\hline Level change ${ }^{a}$ & -0.46 & -1.38 to 0.46 & .339 & -1.43 & -2.53 to -0.33 & .013 \\
\hline Post trend ${ }^{a}$ & -0.19 & -0.31 to -0.07 & $<.001$ & -0.01 & -0.15 to 0.14 & .389 \\
\hline \multicolumn{7}{|c|}{ Aggregate nonpromoted } \\
\hline Baseline level & 31.12 & 29.83 to 32.41 & $<.001$ & & & \\
\hline Pre trend & -0.35 & -0.47 to -0.23 & $<.001$ & -0.10 & -0.25 to 0.06 & .219 \\
\hline Level change ${ }^{a}$ & 2.19 & 0.15 to 4.23 & .044 & 3.04 & 0.39 to 5.69 & .028 \\
\hline Post trenda & -0.19 & -0.48 to 0.10 & .086 & -0.20 & -0.57 to 0.18 & .378 \\
\hline \multicolumn{7}{|l|}{ Antidepressants } \\
\hline Baseline level & 25.83 & 22.40 to 29.26 & $<.001$ & & & \\
\hline Pre trend & 0.04 & -0.27 to 0.35 & .803 & -0.33 & -0.88 to 0.23 & .258 \\
\hline Level change ${ }^{\mathrm{a}}$ & -5.05 & -10.64 to 0.54 & .086 & -11.34 & -20.67 to -2.01 & .020 \\
\hline Post trenda & -0.61 & -1.38 to 0.16 & .009 & 0.71 & -0.67 to 2.10 & .016 \\
\hline \multicolumn{7}{|l|}{ Antihypertensives } \\
\hline Baseline level & 11.58 & 10.29 to 12.87 & $<.001$ & & & \\
\hline Pre trend & 0.11 & 0.00 to 0.23 & .066 & -0.02 & -0.33 to 0.28 & .889 \\
\hline Level change ${ }^{\mathrm{a}}$ & 1.60 & -0.46 to 3.66 & .138 & -2.11 & -7.03 to 2.81 & .404 \\
\hline Post trend ${ }^{\mathrm{a}}$ & -0.36 & -0.65 to -0.07 & $<.001$ & 0.21 & -0.55 to 0.97 & .325 \\
\hline \multicolumn{7}{|c|}{ Lipid-lowering drugs } \\
\hline Baseline level & 62.45 & 59.88 to 65.02 & $<.001$ & & & \\
\hline Pre trend & -0.07 & -0.31 to 0.17 & .572 & -0.32 & -0.69 to 0.05 & .094 \\
\hline Level change ${ }^{a}$ & -3.36 & -7.81 to 1.09 & .150 & -9.98 & -16.80 to -3.16 & .006 \\
\hline Post trend ${ }^{a}$ & -0.66 & -1.24 to -0.09 & .002 & -0.30 & -1.18 to 0.59 & .932 \\
\hline \multicolumn{7}{|l|}{ Respiratory drugs } \\
\hline Baseline level & 48.51 & 43.43 to 53.59 & $<.001$ & & & \\
\hline Pre trend & -0.48 & -0.95 to -0.01 & .053 & -0.73 & -1.27 to -0.18 & .012 \\
\hline Level change ${ }^{\mathrm{a}}$ & 2.11 & -6.59 to 10.81 & .638 & 3.88 & -6.21 to 13.97 & .454 \\
\hline Post trend ${ }^{a}$ & -0.10 & -1.23 to 1.03 & .272 & 0.03 & -1.29 to 1.35 & .060 \\
\hline
\end{tabular}

a Changes after policy implementation.

Note: Baseline level = prescribing rate at month 1 (April 2004); pre trend = monthly change in prescribing rate in period before policy implementation; leve change $=$ change in prescribing rate immediately before policy implementation (September 2005) to immediately after policy implementation (April 2006); post trend $=$ monthly change in prescribing rate in period after policy implementation. MMG relative to control estimates are interpreted similarly, but adjusted for concurrent prescribing trends in the control group.

respiratory drug use was observed immediately after policy implementation in isolation and relative to the control series. This immediate reduction was followed by an increase in the post trend that was nearly significant relative to the control group.

Table 2 shows trend analyses related to the proportion of promoted drug use. A significant reduction in the level change of all promoted drug prescribing was observed after policy implementation. Conversely, the level of nonpromoted branded drug use increased significantly relative to the control group immediately after the drug sample prohibition. These trends are graphically depicted in Figure 1. Relative to the control group, the level of promoted antidepressant prescribing declined significantly after policy implementation but was observed to rebound with a significant increase in trend after policy implementation. The level of promoted lipid-lowering drug prescribing decreased significantly after policy implementation relative to the control group. Figure 2 shows the trends in branded and promoted lipid-lowering drug use among the study and control groups.

Average costs per prescription are shown in Table 3. Aggregate prescription drug cost increased significantly after policy implementation and relative to the control group. Results within specific drug classes were variable. Whereas a significant level change in lipidlowing drug costs was not observed immediately, a significant reduction in the trend of costs for this drug class was observed after policy implementation. Finally, 
Figure 1. Trends in promoted and nonpromoted use among Madras Medical Group (MMG) and control groups (shaded area indicates excluded transition data).

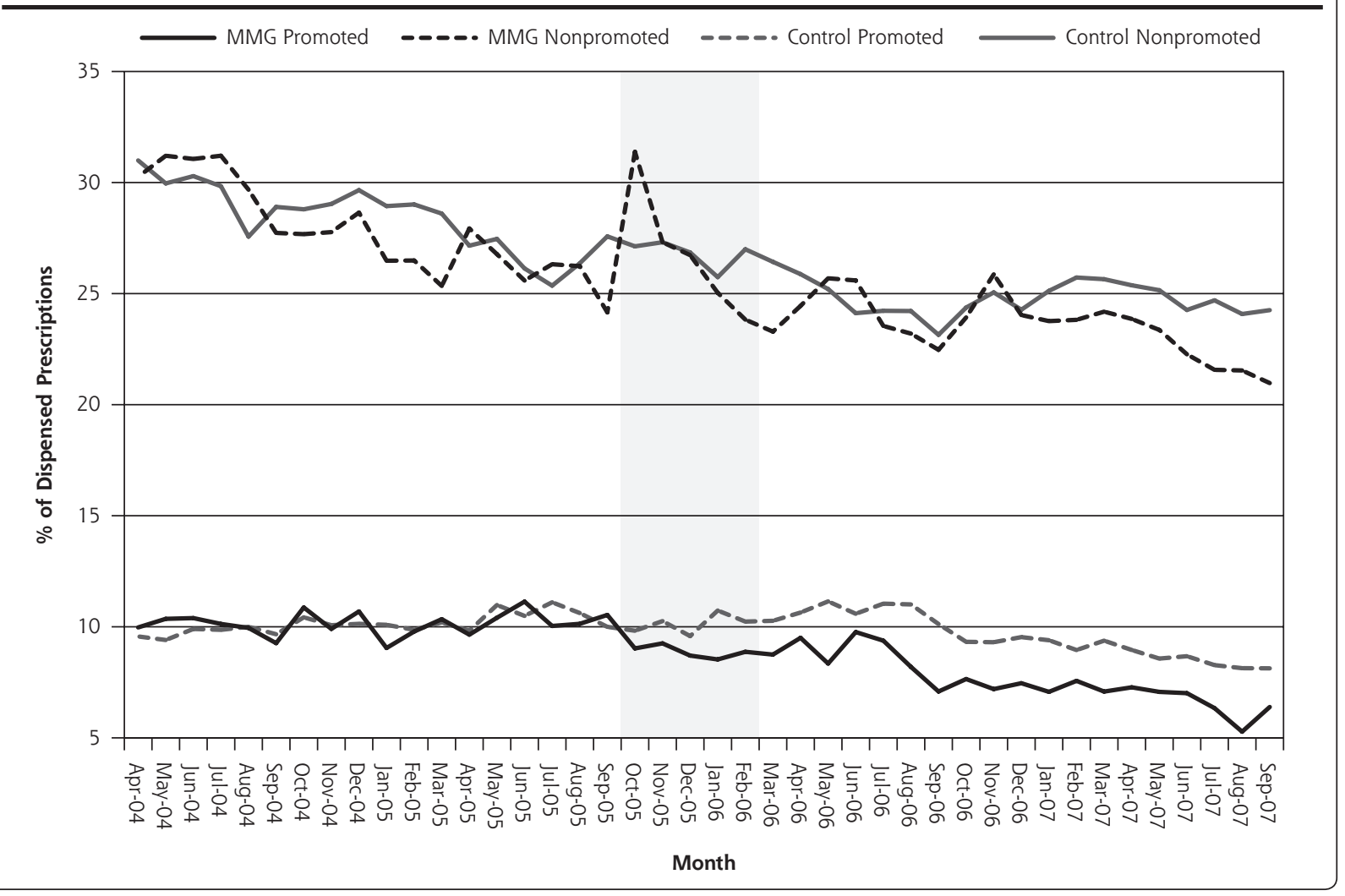

Figure 2. Trends in branded and promoted lipid-lowering drug use among Madras Medical Group (MMG) and control groups (shaded area indicates excluded transition data).

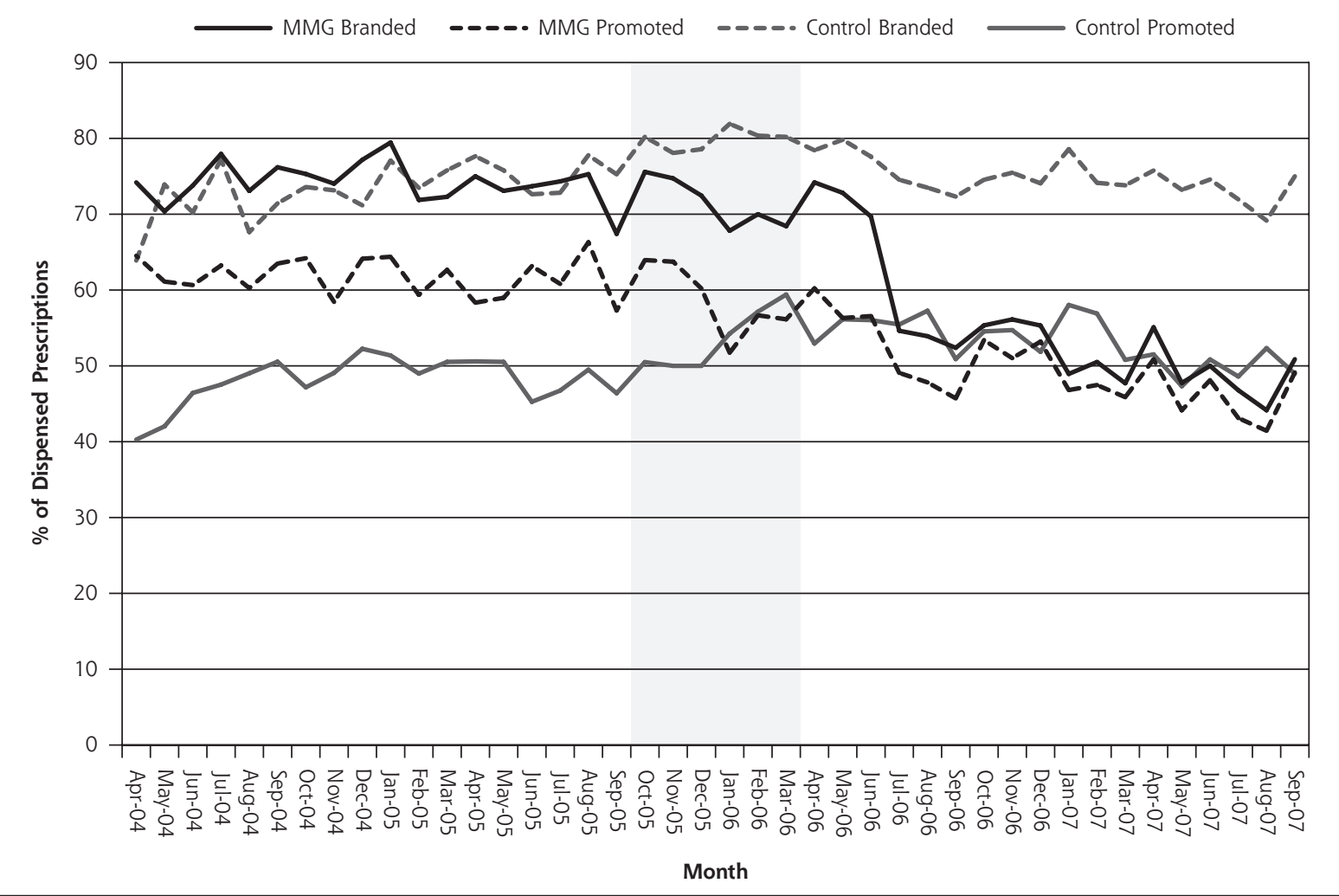




\begin{tabular}{|c|c|c|c|c|c|c|}
\hline \multirow[b]{2}{*}{ Prescribing } & \multicolumn{3}{|c|}{ MMG Trend } & \multicolumn{3}{|c|}{ MMG Relative to Control } \\
\hline & $\begin{array}{c}\text { Estimate } \\
\$\end{array}$ & $95 \% \mathrm{Cl}$ & $P$ Value & $\begin{array}{c}\text { Estimate } \\
\$\end{array}$ & $95 \% \mathrm{Cl}$ & $P$ Value \\
\hline \multicolumn{7}{|l|}{ Aggregate } \\
\hline Baseline level & 37.94 & 36.43 to 39.45 & $<.001$ & & & \\
\hline Pre trend & -0.30 & -0.44 to -0.16 & $<.001$ & -0.51 & -0.70 to -0.32 & $<.0001$ \\
\hline Level change ${ }^{a}$ & 2.84 & 0.24 to 5.45 & .041 & 5.18 & 1.71 to 8.65 & .005 \\
\hline Trend change ${ }^{a}$ & -0.15 & -0.49 to 0.18 & .159 & -0.28 & -0.73 to 0.18 & .091 \\
\hline \multicolumn{7}{|l|}{ Antidepressants } \\
\hline Baseline level & 37.70 & 34.56 to 40.84 & $<.001$ & & & \\
\hline Pre trend & -0.34 & -0.63 to -0.05 & .027 & -0.46 & -0.81 to -0.12 & .010 \\
\hline Level change $^{\mathrm{a}}$ & -1.80 & -7.17 to 3.56 & .515 & -5.96 & -12.35 to 0.43 & .072 \\
\hline Post trend ${ }^{a}$ & -0.16 & -0.86 to 0.55 & .377 & 0.22 & -0.61 to 1.05 & .007 \\
\hline \multicolumn{7}{|l|}{ Antihypertensives } \\
\hline Baseline level & 16.45 & 15.85 to 17.05 & $<.001$ & & & \\
\hline Pre trend & -0.03 & -0.09 to 0.02 & .285 & -0.10 & -0.20 to 0.00 & .059 \\
\hline Level change $^{\mathrm{a}}$ & -0.86 & -1.90 to 0.19 & .118 & -1.31 & -3.20 to 0.59 & .181 \\
\hline Post trend ${ }^{a}$ & -0.06 & -0.19 to 0.07 & .484 & 0.02 & -0.22 to 0.27 & .094 \\
\hline \multicolumn{7}{|c|}{ Lipid-lowering drugs } \\
\hline Baseline level & 80.04 & 76.85 to 83.23 & $<.001$ & & & \\
\hline Pre trend & -0.07 & -0.37 to 0.22 & .632 & -0.01 & -0.41 to 0.39 & .955 \\
\hline Level change ${ }^{a}$ & -1.93 & -7.41 to 3.56 & .497 & 2.38 & -5.04 to 9.79 & .532 \\
\hline Post trend ${ }^{\mathrm{a}}$ & -0.67 & -1.38 to 0.04 & .009 & -0.71 & -1.67 to 0.24 & .016 \\
\hline \multicolumn{7}{|l|}{ Respiratory drugs } \\
\hline Baseline level & 81.47 & 76.75 to 86.19 & $<.001$ & & & \\
\hline Pre trend & -0.25 & -0.69 to 0.18 & .267 & -0.67 & -1.29 to -0.06 & .036 \\
\hline Level change ${ }^{a}$ & -3.57 & -11.70 to 4.56 & .396 & -0.47 & -11.84 to 10.91 & .936 \\
\hline Post trend ${ }^{a}$ & -0.08 & -1.13 to 0.97 & .595 & -0.28 & -1.76 to 1.21 & .373 \\
\hline
\end{tabular}

a significant increase in the trend of average prescription drug costs for antidepressants, relative to the control group, was noted after policy implementation.

\section{DISCUSSION}

In this study, implementation of policies restricting access of pharmaceutical sales representatives to the MMG family practice clinics and elimination of drug samples were associated with modest reductions in the use of branded and promoted pharmaceuticals within several studied drug classes. Drugs for lowering cholesterol were the most consistently affected across all 3 study metrics. Trends in promoted drug use appear to have been a more sensitive indicator of response to the policy than overall branded drug market share, as 3 of 4 classes exhibited some evidence of reduced use. Promoted agents, as a proportion of all prescriptions dispensed, declined significantly, whereas branded non- promoted agents increased significantly immediately after policy implementation, suggesting an immediate substitution effect.

A consistent pattern of drug use emerged in the analysis of promoted drugs overall, and within the antidepressant, antihypertensive, and lipid-lowering drug classes relative to the control group. These drug classes had not only level change reductions after the policy introduction but also increases in the monthly trend during the follow-up period. This pattern of use perhaps reflects an immediate reduction attributable to eliminating samples, with a subsequent rebound to prescribing behavior found before the policy.

There was considerable variation in response to the policy among the studied classes. This variation may be related to the relative number of low-cost agents that could be substituted within each class, as well as clinician perceptions of homogeneity of the class. For example, the reduced use of branded and 
promoted lipid-lowering agents may reflect the relative interchangeability of statins in this class and the availability of generic lovastatin during the study period. Paradoxically, trends in cost per prescription were not consistent with data based on brand and promoted drug market share. Our models detected a positive level change alone and relative to the control group in the average costs per prescription. This finding could potentially be interpreted as a prescribing response to sampled drugs that were no longer available in the clinic. Even so, this pattern of response was not observed consistently across the other drug classes that were examined. For example, for lipid-lowering agents there was a significant decrease in the monthly cost per prescription after the intervention period.

Miller et al evaluated the impact of removing drug samples in an academically affiliated ambulatory internal medicine clinic among uninsured or Medicaidinsured patients using 4 classes of drugs for chronic diseases. ${ }^{20}$ This study found that among uninsured patients the use of generic medications was 4.5 times more likely after removal of the sample closet. The rate of generic prescribing did not change significantly among Medicaid patients. The relatively modest changes found in our study may reflect that uninsured patients represent a minority of those cared for at MMG. An analysis of 3 outpatient family practice residency programs with differing sampling policies found that the program prohibiting samples had the highest rate of generic nonsteroidal anti-inflammatory drug prescribing, but no significant differences in antibiotic or antihypertensive prescribing. ${ }^{21}$ Although evidence shows the availability of samples is associated with increased use of sampled and branded medicines (decreased generic use), the differences in comparative studies are not large, typically less than a $10 \%$ in the measured prescribing rate (eg, generic rate). Our study corroborates these data while controlling for secular trends in prescribing newly offpatent generic agents. This study also suggests that the effect of restrictions on detailing and samples is relatively abrupt. Because both detailing and samples were removed simultaneously, it is not possible to disentangle their component influence.

This study has a number of limitations potentially affecting internal and external validity. An important consideration when evaluating time series data is confounding resulting from secular changes in prescribing The best way to control for such threats to validity is to include a contemporaneous control group of patients or clinicians also experiencing this potential confounder. The most important confounding policy change occurring was implementation of the Medicare Part D program. The control group in this study consisted of a regionally discrete sample of Medicaid enrollees who were not also enrolled in Medicare. Inclusion of control patients who had dual Medicare/ Medicaid enrollment would have introduced spurious shifts in prescribing trends attributable to the loss of claim capture in the Medicaid system. We were unable to apply the same exclusions for the MMG group because of data limitations. We believe that inclusion of the dual-eligible patients in the MMG group would not negate our findings because Medicare patients before implementation of Part D would likely be on lower cost generic drugs, and acquiring drug coverage through a Part D plan would likely only promote greater branded drug use.

Claims for this analysis were obtained from an independent pharmacy in the Madras area where, according to clinicians, most patients had their prescriptions filled. Although it is possible that some prescriptions would not have been captured by using data from only one pharmacy, it seems unlikely that this subset would have introduced any systematic bias or loss of generalizability. Finally, our study examined only trends in all dispensed prescriptions. It is possible that our focus may be relatively insensitive to some types of prescribing changes that could occur in response to pharmaceutical industry marketing restrictions. For example, it is conceivable that removing drug samples would have more impact on the diffusion of newly approved drugs than it would on existing products that clinicians have already incorporated into their therapeutic toolbox.

In summary, this study suggests that restrictions on industry detailing and samples in a family practice clinic had modest and variable effects on reducing branded and promoted drug prescribing. From the perspective of the pharmaceutical industry, the primary purpose of prescription drug samples is providing clinicians and patients with ready access to experience new treatment options. ${ }^{22}$ Samples are also defended because they are helpful for patients who cannot afford their required medications. ${ }^{22}$ Tjia and colleagues reported that nearly one-half of all Medicare recipients before Part D received drug samples, and those reporting cost-related adherence problems were more than 4 times more likely to use samples than patients without problems. ${ }^{23}$ Other research, however, suggests that samples are more likely to go to patients with insurance or higher incomes. ${ }^{24,25}$ Alexander et al observed that receipt of a prescription drug sample was associated with increases in both out-of-pocket and total drug costs. ${ }^{26}$ Additionally, patients receiving a sample were less likely to continue the medication compared with those starting the same medication with a prescription, suggesting receipt of sample is a detriment to adherence. These findings support the assertion that pharmaceutical samples are 
primarily for marketing. Accordingly, clinics considering similar restrictions should evaluate both the positive and negative roles samples and industry representatives play on patient care. Because similar policies may be increasingly adopted by both academic and nonacademically affiliated medical clinics, future research should be directed at exploring patient outcomes associated with these restrictions. ${ }^{27}$

To read or post commentaries in response to this article, see it online at http://www.annfammed.org/cgi/content/full/8/5/402.

Key words: Health care delivery; health services research; health policy

Submitted June 23, 2009; submitted, revised, January 15, 2010; accepted January 29, 2010.

Financial support: Funded in part by an AAFP Foundation Research Stimulation Grant (G0807RS).

Acknowledgments: Thanks to Luke Middleton for his assistance in preparing the claims data for analysis. We would like to thank Jeanne Mendazona, RPh, for her assistance extracting the pharmacy claims data.

\section{References}

1. Donohue JM, Cevasco M, Rosenthal MB. A decade of direct-to-consumer advertising of prescription drugs. N Engl J Med. 2007;357(7): 673-681.

2. Gagnon MA, Lexchin J. The cost of pushing pills: a new estimate of pharmaceutical promotion expenditures in the United States. PLoS Med. 2008;5(1):e1.

3. Avorn J, Chen M, Hartley R. Scientific versus commercial sources of influence on the prescribing behavior of physicians. Am J Med. $1982 ; 73(1): 4-8$

4. Chew LD, O'Young TS, Hazlet TK, Bradley KA, Maynard C, Lessler DS. A physician survey of the effect of drug sample availability on physicians' behavior. J Gen Intern Med. 2000;15(7):478-483.

5. Lexchin J. Interactions between physicians and the pharmaceutical industry: what does the literature say? CMAJ. 1993;149(10):1401-1407.

6. Lurie N, Rich EC, Simpson DE, et al. Pharmaceutical representatives in academic medical centers: interaction with faculty and housestaff. J Gen Intern Med. 1990;5(3):240-243.

7. Orlowski JP, Wateska L. The effects of pharmaceutical firm enticements on physician prescribing patterns. There's no such thing as a free lunch. Chest. 1992;102(1):270-273.

8. Peay MY, Peay ER. The role of commercial sources in the adoption of a new drug. Soc Sci Med. 1988;26(12):1183-1189.

9. Symm B, Averitt M, Forjuoh SN, Preece C. Effects of using free sample medications on the prescribing practices of family physicians. J Am Board Fam Med. 2006;19(5):443-449.
10. Blake RL Jr, Early EK. Patients' attitudes about gifts to physicians from pharmaceutical companies. J Am Board Fam Pract. 1995;8(6): 457-464.

11. Blumenthal D. Doctors and drug companies. N Engl J Med. 2004; 351(18):1885-1890.

12. Brett AS, Burr W, Moloo J. Are gifts from pharmaceutical companies ethically problematic? A survey of physicians. Arch Intern Med. 2003;163(18):2213-2218

13. Choudhry NK, Stelfox HT, Detsky AS. Relationships between authors of clinical practice guidelines and the pharmaceutical industry. JAMA. 2002;287(5):612-617.

14. Eaton L. Readers want transparency in link between doctors and drug firms. BMJ. 2003;326(7403):1352.

15. Scherer FM. The pharmaceutical industry-prices and progress. N Engl J Med. 2004;351(9):927-932.

16. Stelfox HT, Chua G, O'Rourke K, Detsky AS. Conflict of interest in the debate over calcium-channel antagonists. N Engl J Med. 1998; 338(2):101-106.

17. Studdert DM, Mello MM, Brennan TA. Financial conflicts of interest in physicians' relationships with the pharmaceutical industry-selfregulation in the shadow of federal prosecution. $N$ Engl J Med. 2004;351(18):1891-1900.

18. Coleman DL, Kazdin AE, Miller LA, Morrow JS, Udelsman R. Guidelines for interactions between clinical faculty and the pharmaceutical industry: one medical school's approach. Acad Med. 2006;81 (2):154-160.

19. Wagner AK, Soumerai SB, Zhang F, Ross-Degnan D. Segmented regression analysis of interrupted time series studies in medication use research. J Clin Pharm Ther. 2002;27(4):299-309.

20. Miller DP, Mansfield RJ, Woods JB, Wofford JL, Moran WP. The impact of drug samples on prescribing to the uninsured. South Med J. 2008;101(9):888-893.

21. Brewer D. The effect of drug sampling policies on residents' prescribing. Fam Med. 1998;30(7):482-486.

22. PhRMA. PhRMA Defends Distribution of Pharmaceutical Samples; 2008. http://www.phrma.org/news_room/press_releases/phrma_ defends_distribution_of_pharmaceutical_samples.

23. Tjia J, Briesacher BA, Soumerai SB, et al. Medicare beneficiaries and free prescription drug samples: a national survey. J Gen Intern Med. 2008;23(6):709-714.

24. Cutrona SL, Woolhandler S, Lasser KE, et al. Free drug samples in the United States: characteristics of pediatric recipients and safety concerns. Pediatrics. 2008;122(4):736-742

25. Cutrona SL, Woolhandler S, Lasser KE, Bor DH, McCormick D, Himmelstein DU. Characteristics of recipients of free prescription drug samples: a nationally representative analysis. Am J Public Health. 2008;98(2):284-289.

26. Alexander GC, Zhang J, Basu A. Characteristics of patients receiving pharmaceutical samples and association between sample receipt and out-of-pocket prescription costs. Med Care. 2008;46(4):394-402.

27. Brennan TA, Rothman DJ, Blank L, et al. Health industry practices that create conflicts of interest: a policy proposal for academic medical centers. JAMA. 2006;295(4):429-433. 